This manuscript was accepted and published by Energy \& Fuels, a journal of the American Chemical Society. Publication data of the final, corrected work:

Wang, L.; Várhegyi, G.; Skreiberg, Ø.; Li, T.; Grønli, M.; Antal, M. J.: Combustion characteristics of biomass charcoals produced at different carbonization conditions. A kinetic study. Energy Fuels 2016, 30, 3186-3197. doi: 10.1021/acs.energyfuels.6b00354

\title{
Combustion Characteristics of Biomass Charcoals Produced at Different Carbonization Conditions. A Kinetic Study
}

Liang Wang ${ }^{\dagger}$, Gábor Várhegyi ${ }^{\star * *}, \varnothing y v i n d$ Skreiberg ${ }^{\dagger}$, Tian Li $^{\S}$, Morten Grønli ${ }^{\S}$ and Michael J. Antal, Jr. ${ }^{\| 1}$

† SINTEF Energy Research, Postboks 4761 Sluppen, NO-7465 Trondheim, Norway

* Institute of Materials and Environmental Chemistry, Research Centre for Natural Sciences, Hungarian Academy of Sciences, PO Box 286, Budapest, Hungary 1519

$\S^{\S}$ Department of Energy and Process Engineering, Norwegian University of Science and Technology (NTNU), NO-7491 Trondheim, Norway

"Hawaii Natural Energy Institute, University of Hawaii at Manoa, Honolulu, Hawaii 96822, United States

* To whom correspondence should be addressed.

Email: varhegyi.gabor@t-online.hu or gvarhegyi@gmail.com

${ }^{1}$ Deceased on October 21, 2015.

KEYWORDS: Spruce, forest residue, biomass, char, combustion, kinetics, reactivity, thermogravimetry.

ABSTRACT. The combustion properties of spruce chars and spruce forest residue chars were studied in the kinetic regime by a series of TGA experiments. The work aimed at establishing how the pressure of the char preparation affects the reactivity with oxygen. Parts of the chars were prepared from a thin layer of biomass in inert gas flow at atmospheric pressure and at $0.8 \mathrm{MPa}$. Other chars were formed in a pressurized reactor by a flash carbonization method [Antal et al., Ind. Eng. Chem. Res. 42 (2003) 3690-3699]. Despite the differences 
in the preparation, remarkable similarities were observed in the combustion behavior of the samples. The kinetics of the char burn-off was described by assuming three partial reactions. 18 experiments at three different temperature programs were evaluated by the method of least squares to obtain dependable kinetic model variants. A common activation energy of $150 \mathrm{~kJ} / \mathrm{mol}$ gave a reasonable description for the three partial reactions in all experiments.

\section{INTRODUCTION}

Biomass charcoal has favorable properties for combustion applications. Usually they contain less ash and nitrogen and much less sulfur than coals. On the other hand, their energy density is the highest among the biomass fuels. The combustion characteristics of biomass charcoal are influenced by the chemical and physical properties of the raw biomass and depend on the parameters of the carbonization process, too. There are charcoal fabrication methods employing elevated pressure that result in particularly high charcoal and fixed carbon yields. ${ }^{1,2}$

Concerning the raw materials, the forest residues are particularly interesting due to their low cost and high abundance. Forest residues are derived from the crown and branches of trees, including usually needles and foliage. In Norway alone, a maximum annual energy production of 5.3 TWh from forest residues could be possible with the present harvest level, ${ }^{3}$ while this could be increased to $10 \mathrm{TWh}$ at a sustained yield harvest level. ${ }^{4}$

With its high precision and well-controlled experimental conditions, TGA (thermogravimetric analysis) is a useful tool for studying the combustion of solid fuels in the kinetic regime. ${ }^{5}$ However, a TGA can be employed only at relatively low heating rates as the true temperature of the samples becomes unknown at high heating rates. Accordingly the results of the TGA studies cannot be utilized directly in the modeling of industrial combustors; they serve as basic research to direct further development in the field.

There are several studies on the oxidation kinetics of woody biomass chars at various operating conditions and with different char preparation methods. A major part of the existing knowledge on the burn-off kinetics of biomass chars is summarized in the extensive review of Di Blasi. ${ }^{5}$ When the combustion is in the kinetic regime, the kinetics can usually be well described by the following type of equations: ${ }^{5}$

$$
d \alpha / d t=A \exp (-E / R T) f(\alpha)
$$

where $A$ is the pre-exponential factor, $\alpha$ is the reacted fraction predicted by the kinetic model, and function $f(\alpha)$ approximates the reactivity change of the sample as the gasification proceeds. $A$ obviously depends on 
the partial pressure of the $\mathrm{O}_{2}$. Several theoretical or empirical formulae were proposed for $f(\alpha)$; nowadays the use of a simple n-order kinetics appears to be the most frequent:

$$
d \alpha / d t=A \exp (-E / R T)(1-\alpha)^{n}
$$

The papers published after the review of Di Blasi ${ }^{5}$ are briefly overviewed as follows. Several works carried out kinetic evaluation from a single TGA experiment with a constant heating rate. ${ }^{6-10}$ The main problem with this approach is the limited information content of a single experiment at a constant heating rate. We think that this is the main reason for the wide variety of activation energies obtained in this way: values from 25 till $225 \mathrm{~kJ} / \mathrm{mol}$ were reported in the last six years. ${ }^{6-10}$ Besides, too high sample masses were also employed in most of the works overviewed here though the huge reaction heat of the char $+\mathrm{O}_{2}$ requires particular cautions in this respect. Tushar et al., ${ }^{8}$ for example, used an initial sample mass of $5 \mathrm{mg}$ at a heating rate of $20^{\circ} \mathrm{C} / \mathrm{min}$. Figure 4 in their work reveals that all of their experiments suffered from a spontaneous self-ignition around $400-440^{\circ} \mathrm{C}$ : the self-heating (caused by the huge reaction heat) speeded up the reaction rate, and a considerable part of the sample burned in a split second. This effect appeared as a sudden drop of the sample mass in the TGA curves, as shown in their figures. (We shall deal with the self-heating problems in more details in Section 3.1 of the present work.) A further problem in the work of Tushar et al. ${ }^{8}$ is the reaction order: they obtained $n=3$, while the shape of their mass loss rate curves is not similar to the shape of the thirdorder curves. Note that the shape of the $\mathrm{d} \alpha / \mathrm{dt}$ curves at a constant heating rate is characteristic to the reaction order, as it was established nearly 60 years ago. ${ }^{11}$ Sahu et al. ${ }^{7}$ employed a similarly high sample mass: $10 \mathrm{mg}$ at a heating rate of $10^{\circ} \mathrm{C} / \mathrm{min}$ in synthetic air. Pottmaier et al. ${ }^{9}$ used both isothermal and non-isothermal kinetics assuming $n=1$ in eq 2 . However, the shape of the isothermal mass loss rate curves plotted against the reacted fraction did not correspond to a shape expectable at first order kinetics (or any $n$-order kinetics): Figures 9 and 10 in their work show characteristic maximum curves.

Tilghman and Mitchell ${ }^{12}$ studied the gasification of a coal char and a biomass char by various mixtures of gases. The results were interpreted by 18 elementary reactions for which the kinetic data were obtained from earlier works since 1960. The part dealing with combustion was based on isothermal experiments on 400 , 450,500 and $550^{\circ} \mathrm{C}$ in 6 and $12 \% \mathrm{O}_{2}$. The initial sample mass of the chars was $5 \mathrm{mg}$ which appears to be too high, especially in the higher parts of their temperature domains. (See e.g. Section 3.1 in the present work.) Besides, the reactivities of the coal char and the biomass char were found to be unusually close to each other, compared to such TGA works on coal chars and biomass chars which were carried out with much smaller sample masses. ${ }^{13,14}$

Li et al. ${ }^{15}$ employed an isothermal plug flow reactor to study the high temperature reactions of two biomass chars. Under these conditions, however, the diffusion played an important role in the kinetics, as outlined in their model. Consequently, rather low apparent activation energies were obtained, 48 and $60 \mathrm{~kJ} / \mathrm{mol}$. 
Concerning the isothermal kinetics by TGA, Naredi et al. ${ }^{16}$ studied the transient time during the switch from an inert gas to a reactive one. They observed a transient time of 22 minutes in a $\mathrm{CO}_{2}$ gasification experiment at $850^{\circ} \mathrm{C}$ at a gas flow rate of $100 \mathrm{~mL} / \mathrm{min}$ which went down to 10 minutes at a very high gas flow rate, $300 \mathrm{~mL} / \mathrm{min}$. They proposed a mathematical correction for the kinetic evaluations assuming that the TGA furnace is a well-mixed reactor. In our opinion, however, one can avoid a mathematical correction based on this assumption if the sample is heated up in the reactive gas and the kinetic evaluation includes the heat up period, too. Note that a kinetic evaluation can be carried out at any $\mathrm{T}(\mathrm{t})$ if the kinetic equations are solved numerically along the experimental $\mathrm{T}(\mathrm{t})$ functions. The use of only the isothermal sessions after the heat-up (or after achieving perfect gas mixing) is an unnecessary limitation for the planning and use of the experiments.

The present work aims at

- Studying the effect of pressure during the char preparation on the reactivity of the formed chars.

- Comparing the properties of wood chars and forest residue chars.

- Establishing dependable kinetic descriptions of the char combustion in the kinetic regime.

- Establishing proper evaluation methods to achieve the previous goal when half of the chars were prepared from a highly inhomogeneous raw material (forest residue) while one of the preparation methods can add further inhomogeneities into the char.

This work is dedicated to the memory of Michael J. Antal, who participated in our project till the last days of his life.

\section{SAMPLES AND METHODS}

2.1 Sample Preparation. The stem wood and forest residues (containing branches, tops and needles) originated from a Norway spruce forest in South Norway (Latitude $59^{\circ} 38^{\prime} \mathrm{N}$, Longitude $09^{\circ} 09^{\prime} \mathrm{E}$ ) from stands with an average site quality. The harvested trees were divided into three parts including stem wood, forest residue (i.e., tops and branches), and roots. The stem wood and forest residue were chipped for the present study. They were dried at $105{ }^{\circ} \mathrm{C}$ for 24 hours before using.

Part of the chars was prepared in a thermobalance, because the char formation is particularly well defined in that way. The raw materials were milled below $1 \mathrm{~mm}$, and heated by $10^{\circ} \mathrm{C} / \mathrm{min}$ till $500^{\circ} \mathrm{C}$ in an open sample pan to form char. A high-pressure thermogravimetric analyzer was employed (LINSEIS STA HP) which was operated either at atmospheric pressure or at 8 bar $(0.8 \mathrm{MPa})$ in the present study. The notation of the obtained samples includes an abbreviation for the raw materials ( $\mathrm{S}$ for spruce and $\mathrm{R}$ for forest residue), the temperature of the char formation $\left(500^{\circ} \mathrm{C}\right)$ and the pressure $(1$ and 8 bar, where " 1 bar" is the rounded value of the atmospheric pressure). Hence, these chars are denoted as S500-1, S500-8, R500-1 and R500-8. 
Chars were also prepared in a bench-scale flash carbonization reactor. ${ }^{2,17} 0.7 \mathrm{~kg}$ feedstock was placed into a cylindrical canister. The canister was subsequently loaded into the top of the flash carbonization reactor that was then pressurized with air. Electric power was delivered for $360 \mathrm{~s}$ to a heating coil at the bottom of the reactor to ignite the wood at the bottom of the canister. Following ignition, compressed air was delivered to the top of the reactor and flowed downward through the packed bed while the flash fire moved upward. The pressure within the reactor was continuously monitored and maintained at 7.9 bar (115 psi) by a valve located downstream of the reactor. After sufficient air was delivered, the airflow was halted, and the reactor cooled overnight. The charcoal product was removed from the reactor and was allowed to equilibrate under a fume hood for 2 days before proximate analysis was performed. The charcoal yield from the wood and the forest residue was $24.1 \%$ and $30.5 \%$. Earlier studies showed that the chars originating from the top, middle and bottom parts of a flash carbonization reactor have different properties. ${ }^{14}$ In the present work the chars from the middle part of the canister were used. These samples are denoted by $\mathbf{S f c - 8}$ and $\mathbf{R f c - 8}$, where number 8 is a rounded value of the 7.9 bar operation pressure.

2.2. Characterization of the Raw Materials and the Formed Chars. The raw materials (pre-dried stem wood and forest residue) were subjected to proximate analysis according to ASTM standards E871 and E872, while the ash content was measured by ASTM D1102. The flash carbonization charcoals were ground in a corundum mortar, then they were subjected to proximate analysis according to ASTM standard D1762-84. The chars produced in the TGA were available only in smaller quantities, hence their proximate analyses were carried out by ASTM standard E1103-08 with a TGA. Their ash content was also determined in a TGA. The results are shown in Table 1. The data indicate that the degree of carbonization is the highest in the flash carbonization chars and the lowest in the atmospheric pressure TGA chars.

The inorganic element compositions were analyzed by inductively coupled plasma optical emission spectrometry (ICP-OES) according to standard CEN/TS 15290:2006. The corresponding results are shown for the raw materials in Table 2. The char samples contained these elements in approximately the same ratios as the raw materials of which they were formed. The values in Table 2 are similar to those obtained for Norway spruce and forest residue from another part of the country, ${ }^{18}$ except that the present stem wood contains more ash $(0.6$ vs $0.3 \%)$, hence the concentrations of the listed elements are higher in the present case. 
Table 1: Proximate and ultimate analyses of the raw materials and chars ${ }^{\text {a }}$

\begin{tabular}{lccc}
\hline Sample & \multicolumn{3}{c}{ Proximate analysis } \\
& VM & fC & Ash \\
\hline Wood & 83.4 & 16.0 & 0.6 \\
Forest residue & 76.8 & 20.7 & 2.5 \\
S500-1 & 24.5 & 74.4 & 1.1 \\
S500-8 & 20.1 & 78.4 & 1.5 \\
Sfc-8 & 18.1 & 80.2 & 1.7 \\
R500-1 & 19.8 & 77.3 & 2.9 \\
R500-8 & 16.5 & 80.2 & 3.3 \\
Rfc-8 & 12.0 & 83.8 & 4.2 \\
\hline
\end{tabular}

a See the employed methods in the text. $\mathbf{b} \%(\mathrm{~m} / \mathrm{m})$, dry basis.

Table 2. The Concentration of Ash Forming Elements in the Raw Materials ${ }^{a, b}$

\begin{tabular}{lrrr}
\hline & $\begin{array}{r}\text { Forest } \\
\text { residue }\end{array}$ & Wood & Ratio $^{\mathbf{c}}$ \\
\hline $\mathrm{Ca}$ & 6004 & 1948 & 3.1 \\
$\mathrm{Si}$ & 571 & 73 & 7.8 \\
$\mathrm{~K}$ & 2516 & 672 & 3.7 \\
$\mathrm{Mg}$ & 649 & 212 & 3.1 \\
$\mathrm{P}$ & 349 & 61 & 5.7 \\
$\mathrm{Na}$ & 48 & 42 & 1.1 \\
$\mathrm{Fe}$ & 113 & 39 & 2.9 \\
$\mathrm{Mn}$ & 877 & 323 & 2.7 \\
$\mathrm{~S}$ & 380 & 80 & 4.8 \\
$\mathrm{Al}$ & 93 & 31 & 3.0 \\
$\mathrm{Zn}$ & 80 & 31 & 2.6 \\
$\mathrm{Ba}$ & 87 & 41 & 2.1 \\
\hline
\end{tabular}

${ }^{\mathbf{a}} \mathrm{ppm}$ (mg/kg, dry basis). ${ }^{\mathbf{b}}$ Measured by ICP-OES according to standard CEN/TS 15290:2006. ${ }^{\mathbf{c}}$ Ratio of the concentrations of the forest residue and the wood. 
The microstructure, surface morphology and size of the char particles were investigated by scanning electron microscopy (Hitachi S-3400N). Figure S2 in the Supporting Information compares the SEM micrographs of the atmospheric pressure TGA chars to that of the flash carbonization chars. These micrographs show more or less the remnants of the plant fibers together with a few larger morsels. The flash carbonization chars, however, contain a larger fraction of smaller or thinner particles than the atmospheric pressure TGA chars. Sample S500-1 shows typical woody biomass structure with the presence of long fibers which did not appear at the flash carbonization chars.

2.3. Reactivity Studies. The chars were burned off in another TGA (Q5000 IR analyzer of TA instruments). Small sample masses $(0.2-1 \mathrm{mg})$ and a $100 \mathrm{~mL} / \mathrm{min}$ gas flow of $20 \%$ oxygen $-80 \%$ nitrogen were employed. Three different temperature programs were used: linear $\mathrm{T}(\mathrm{t})$ with a heating rate of $10^{\circ} \mathrm{C} / \mathrm{min}$; modulated experiments where a sine function with $5^{\circ} \mathrm{C}$ peak amplitude and $200 \mathrm{~s}$ wavelength was added to a $5^{\circ} \mathrm{C} / \mathrm{min}$ linear $\mathrm{T}(\mathrm{t})$; and constant reaction rate $(\mathrm{CRR}) \mathrm{T}(\mathrm{t})$. In the latter case the equipment regulated the heating of the samples so that the reaction rate remained below a small preset limit. ${ }^{19}$ This type of measurements falls into the category of the controlled rate thermal analysis (CRTA) by the current IUPAC nomenclature. ${ }^{20}$ The employment of the different heating programs served to increase the information content of the experiments for the kinetic evaluation. ${ }^{13,14,18,21}$. The small sample masses and slow heating programs are needed to maintain kinetic control and avoid excessive self-heating and possible self-ignition, as illustrated in section 3.1 The experiments were corrected for baseline shifts and buoyancy effects. The sample mass was normalized by the sample mass observed at $120^{\circ} \mathrm{C}$; the normalized sample mass is denoted as $m$. Here the above value $\left(120^{\circ} \mathrm{C}\right)$ was selected as a temperature safely after the drying period, but still before the chemical reactions. The zero point of the temperature scale of the figures corresponds to $\mathrm{T}=120^{\circ} \mathrm{C}$.

\subsection{Evaluation by the Method of Least Squares and Characterization of the Fit Quality. Fortran 95} and $\mathrm{C}++$ programs were used for the numerical calculations and for graphics handling, respectively. The employed numerical methods have been described in details earlier. ${ }^{22}$ The kinetic evaluation was based on the least squares evaluation of the $-d m^{o b s} / d t$ curves, where $m^{o b s}$ is the sample mass normalized by the initial dry sample mass. The method used for the determination of $-d m^{o b s} / d t$ does not introduce considerable systematic errors into the least squares kinetic evaluation of experimental results. ${ }^{23}$ The least squares evaluation of $-d m^{o b s} / d t$ means that we look for the best approximation of the observed reaction rates. The kinetic models were solved numerically along the empirical temperature - time functions. The minimization of the least squares sum was carried out by a direct search method, as described earlier. ${ }^{22}$ This was based on the HookJeeves algorithm, which is a slow, but "very reliable" numerical method. ${ }^{24}$ 
Such values were searched for the unknown model parameters that minimized the following objective function $(o f)$ :

$$
o f=\sum_{k=1}^{N} \sum_{i=1}^{N_{\text {points }}} \frac{\left[\left(\frac{d m}{d t}\right)_{k}^{\text {obs }}\left(t_{i}\right)-\left(\frac{d m}{d t}\right)_{k}^{\text {calc }}\left(t_{i}\right)\right]^{2}}{N_{\text {points }} h_{k}^{2}}
$$

Here $N$ is the number of experiments evaluated together. $N_{\text {points }}$ denotes the number of $t_{\mathrm{i}}$ time points on a given curve and $m$ is the sample mass normalized by the initial dry sample mass. The division by $h_{k}^{2}$ served to counterbalance the high magnitude differences. $h_{\mathrm{k}}$ was chosen to be the highest observed value of the given experiment:

$$
h_{\mathrm{k}}=\max \left(\frac{d m}{d t}\right)_{k}^{o b s}
$$

The normalization by the highest observed values in the least squares sum assumes implicitly that the relative precision is roughly the same for the different experiments. This assumption has proved to be useful in numerous works on non-isothermal kinetics since $1993 .{ }^{25}$ It is crucial to get suitable starting parameters for the minimization; we have selected starting parameters from our earlier works.

The obtained fit quality can be characterized separately for each of the experiments evaluated together. For this purpose the relative deviation (reldev, \%) was used. The root mean square difference between the observed and calculated values is expressed as percent of peak maximum. For a given experiment (denoted here as experiment $k$ ) we get:

$$
\operatorname{reldev}(\%)=100\left\{\sum_{i=1}^{N_{\text {points }}} \frac{\left[\left(\frac{d m}{d t}\right)_{k}^{o b s}\left(t_{i}\right)-\left(\frac{d m}{d t}\right)_{k}^{\text {calc }}\left(t_{i}\right)\right]^{2}}{N_{\text {points }} h_{k}^{2}}\right\}^{0.5}
$$

The fit quality for a given group of experiments was characterized by the root mean square of the corresponding relative deviations. The relative deviation of three experiments is denoted by reldev $(\%)$ and calculated as the root means square of the reldev values of the individual experiments. Obviously a smaller reldev $_{3}$ value indicates a better fit for the given group of experiments. Similarly, reldev 18 stands for the root mean square reldev for 18 experiments.

2.4. Reaction Kinetic Models. Two empirical approximations were used for the $f(\alpha)$ functions in the present work. The simplest is the $n$-order kinetics (eq 2).

However, the $n$-order kinetics cannot describe the self-accelerations caused by the opening and growth of the internal pores during the burn-off. To check the occurrence of such effect and to describe them approximately the following equation was employed: 
Eq 6 is a special case of a formula that has been used in several gasification and combustion studies since 1996. ${ }^{13}$ In this approximation $n$ and $z$ are formal parameters that define the shape of the corresponding $f(\alpha)$. normfactor normalizes $f(\alpha)$ so that its highest value would be one in the [0,1] interval of $\alpha$. Obviously normfactor is not an independent parameter, it is a simple function of $n$ and $z \cdot{ }^{13}$ There are theoretical models to describe the roles of the internal pores which have been deduced for ideal cases, assuming pure carbon particles of regular shape. ${ }^{26,27}$ The burn-off of a real char, however, differs from the ideal behavior by several complicating factors, including the presence of the mineral matter and the irregular geometry.

The effect of the inhomogeneities on the combustion kinetics was described by supposing three parts with different reactivity (three pseudo-components) in the chars. This assumption proved to be applicable for all chars of this study. Each pseudo-component had its own reacted fraction and its own kinetic equation:

$$
\mathrm{d} \alpha_{\mathrm{j}} / \mathrm{dt}=A_{\mathrm{j}} \exp \left(-E_{j} / R T\right) \mathrm{f}\left(\alpha_{\mathrm{j}}\right) \quad j=1,2,3
$$

The predicted mass loss rate, $-\mathrm{dm}^{\text {calc }} / \mathrm{dt}$, is a weighted sum of the three partial reaction rates:

$$
-d m^{\text {calc }} / d t=\sum_{j=1}^{3} c_{j} d \alpha_{j} / d t
$$

where weight factors $c_{\mathrm{i}}$ are determined together with the other model parameters by the method of least squares.

In the present study all $A$ values belong to $20 \% \mathrm{O}_{2}$ at atmospheric pressure.

\section{RESULTS AND DISCUSSION}

3.1 Effect of the Transport Processes. The charcoal combustion has a huge exothermic reaction heat; the heating value of a typical charcoal is around $28-33 \mathrm{MJ} / \mathrm{kg} .{ }^{28}$ If the sample mass is not sufficiently low for the given heating rate, significant self-heating arises. The problem is illustrated in Figure 1, which compares the burn-off of 0.2 and $0.6 \mathrm{mg}$ spruce char (S500-8) at $10^{\circ} \mathrm{C} / \mathrm{min}$ heating rate. In the experiment with $0.6 \mathrm{mg}$ char the self-heating of the sample resulted in an ignition at $436^{\circ} \mathrm{C}$ which consumed ca. half of the sample within a split second due to the resulting elevated sample temperatures, far from any kinetic and temperature control.

From this respect the CRR experiments are the safest. Their mass loss rate was kept below $0.2 \mu \mathrm{g} / \mathrm{s}$ at an initial sample mass of $1 \mathrm{mg}$, while the peak mass loss rate of the other experiments varied between 0.4 and 0.7 $\mu \mathrm{g} / \mathrm{s}$ at initial sample masses of $0.2-0.5 \mathrm{mg}$. (The peak mass loss rate for the experiment with self-ignition in Figure 1 was found to be much higher, $68 \mu \mathrm{g} / \mathrm{s}$.) The $10^{\circ} \mathrm{C} / \mathrm{min}$ experiments were regarded as the less dependable. Nevertheless, a repeatability can be achieved at this heating rate, too, if the sample mass is 
chosen to a sufficiently low value. An example is shown in the Supporting Information that accompanies this article.

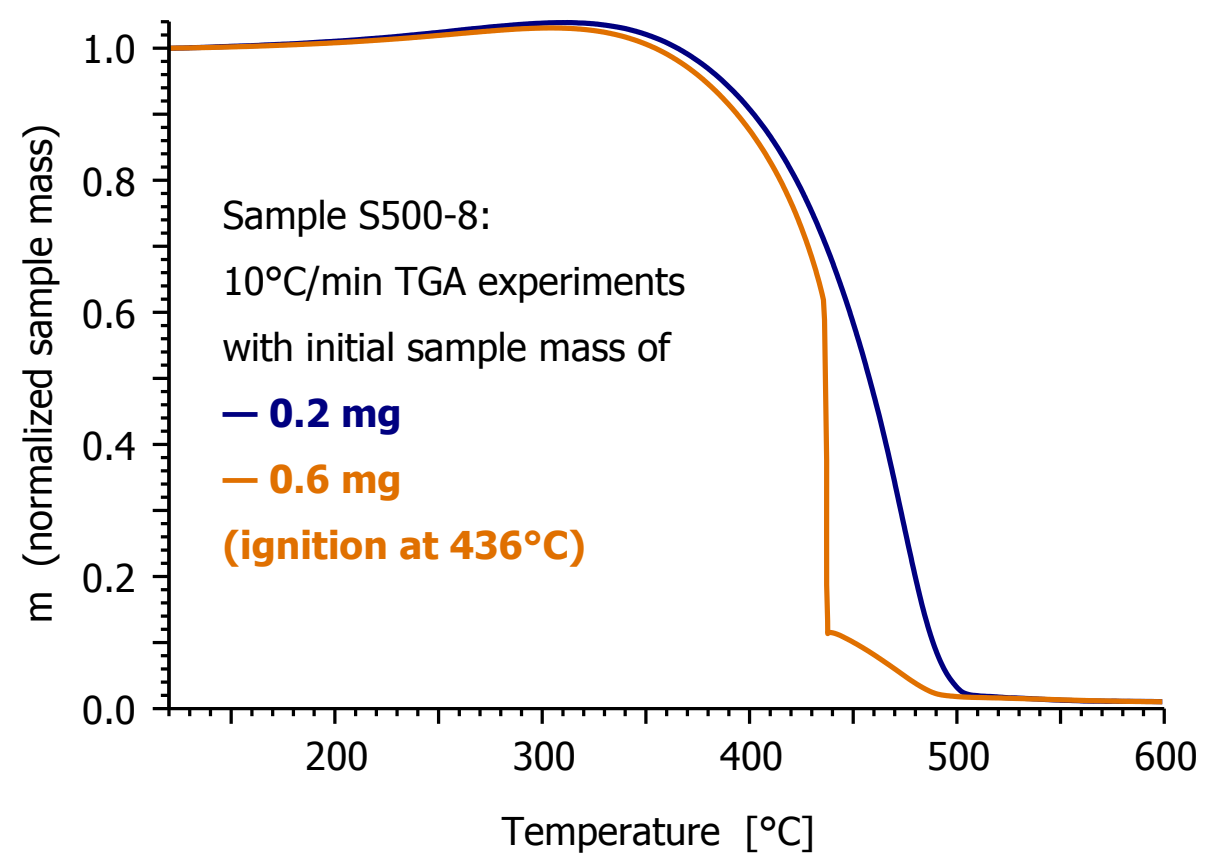

Figure 1. Comparison of the burn-off of 0.2 and $0.6 \mathrm{mg}$ spruce chars in TGA experiments at $10^{\circ} \mathrm{C} / \mathrm{min}$ heating rate.

3.2. Effect of the Preparation on the Reactivity. Figure 2 compares the reactivity of the samples. Due to the reasons outlined in the previous section, the slower heating programs (modulated $5^{\circ} \mathrm{C} / \mathrm{min}$ and $\mathrm{CRR}$ ) are used in the comparison. The plots in Figure 2 clearly indicate that the burn-off of the chars prepared in TGA depends only slightly on the pressure. (See the agreement of the blue dashed lines and dark-blue solid lines, which represent the atmospheric pressure and the 8-bar chars prepared in TGA.) The difference between the 1 and 8-bar chars in Figure 2 are characterized by their mean temperature difference, $\overline{\Delta T}$. For the modulated experiments (Figures 2a and 2c) the time differences of the identical reacted fraction values $(\alpha)$ were calculated, and their means were formed between $\alpha=0.2$ and $\alpha=0.8$. The time differences were converted to temperature by a multiplication of the mean heating rate, $5^{\circ} \mathrm{C} / \mathrm{min}$. In this way $\overline{\Delta T}=-2^{\circ} \mathrm{C}$ were obtained between chars S500-1 and S500-8 in Figure 2a, while the $\overline{\Delta T}$ difference for chars R500-1 and R500-8 was found to be $+3^{\circ} \mathrm{C}$ in Figure $2 \mathrm{c}$.

For the CRR experiments, the differences of the $\mathrm{T}(\mathrm{t})$ programs were calculated in the central parts of the figures, from $\mathrm{t}=60$ minutes till $\mathrm{t}=120$ minutes. $\overline{\Delta T}=-4^{\circ} \mathrm{C}$ and $\overline{\Delta T}=+3^{\circ} \mathrm{C}$ were obtained for the S500-1 $-\mathrm{S} 500$ 8 and R500-1 - R500-8 differences, respectively. Accordingly the pressure had on only small effect on the reactivity of the formed chars. 
The $\overline{\Delta T}$ difference between the flash carbonization spruce char, Sfc-8, and the 8-bar TGA spruce char, S500-8, was $3^{\circ} \mathrm{C}$ for the modulated experiments and $2^{\circ} \mathrm{C}$ for the $\mathrm{CRR}$ experiments. Keeping in mind the huge differences between the preparation of the TGA chars and the flash carbonization chars, these values are surprisingly low. Though the range of the decomposition is wider at Sfc-8 than at the TGA spruce chars, which can be due probably to the lower homogeneity of the char preparation conditions in the flash carbonization reactor.

Higher differences were found between forest residue chars, as reflected by Figures $2 \mathrm{c}$ and $2 \mathrm{~d}$. The $\overline{\Delta T}$ difference between the flash carbonization forest residue char, Rfc-8, and its TGA counterpart, R500-8, was $29^{\circ} \mathrm{C}$ for the modulated experiments and $11^{\circ} \mathrm{C}$ for the CRR experiments. Here one should keep in mind that the temperature programs of the CRR experiments are chosen so that the reaction rates would remain below a preset limit. Accordingly the $\overline{\Delta T}$ values characterize the reactivity differences in different ways in the CRR and the other experiments. 

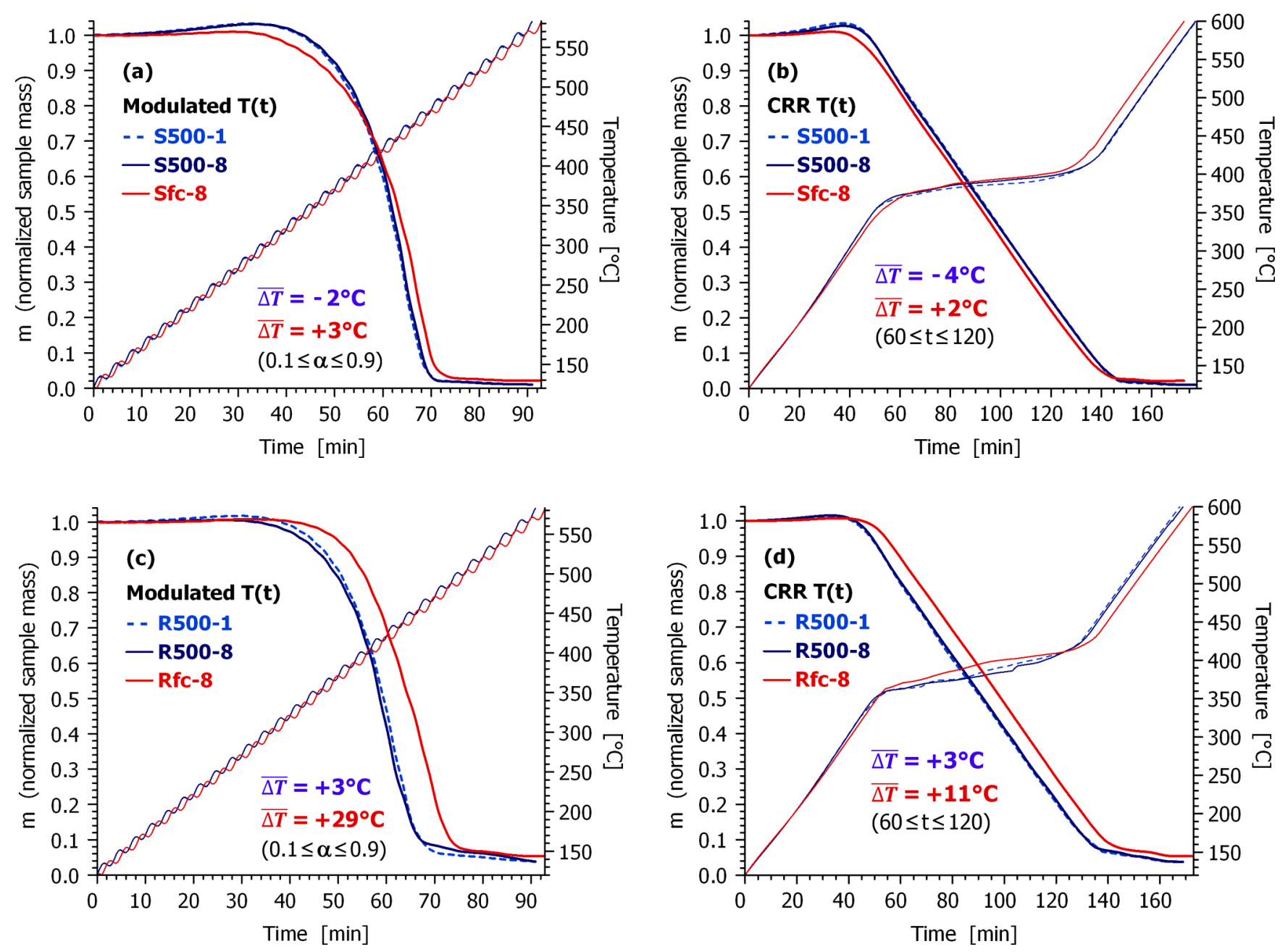

Figure 2. Comparison of the behavior of the samples at the slower heating programs (modulated $5^{\circ} \mathrm{C} / \mathrm{min}$ and CRR). The $m(t)$ and $T(t)$ curves are denoted by thick and thin lines. The curves of the atmospheric-pressure chars are dashed. See the text for further explanations.

3.3. Considerations for the Kinetic Modelling. As Figure 2 shows, the spruce chars prepared in TGA exhibited a marked mass gain at the lower part of the temperature domain. This mass gain can obviously be due to the chemisorption of the oxygen. Figure 2 also shows that the burn-off of the forest residue chars is followed by a slower process which is probably due to the decomposition of various carbonates. It occurs between 500 and $600^{\circ} \mathrm{C}$. (See also Figure 3.) Based on the ICP analyses, shown in Table 2, the decomposition of $\mathrm{Mg}$ and $\mathrm{Mn}$ carbonates can be assumed, because the calcium and potassium carbonates decompose at much higher temperatures. In pure nitrogen, the carbonates of $\mathrm{Mg}$ and $\mathrm{Mn}$ decompose below $500^{\circ} \mathrm{C}^{29}$ However, the char burn-off releases $\mathrm{CO}_{2}$ and the presence of $\mathrm{CO}_{2}$ shifts the decomposition temperatures of the carbonates to higher temperatures. ${ }^{30}$ The modelling of these processes was out of the scopes of the present work. Such domains were selected for the kinetic evaluation in which the char burn-off 
was the dominating process. (See the Supplementary Information, where the kinetic evaluation of all experiments is shown in figures.) The $-d m^{o b s} / d t$ curves were evaluated, as described in Section 2.3. Figure 3 compares the $-d m^{o b s} / d t$ curves of the 8-bar chars at the linear $\mathrm{T}(\mathrm{t})$ program. The burn off of the spruce chars (olive and orange lines) exhibited sharper, more regular peaks than that of the forest residue chars (dark blue and magenta lines). Nevertheless, none of the samples could be described well by only one kinetic equation. Much better fit quality was observed when three partial reactions were assumed. (See equations 7 and 8 in Section 2.4.) For a simpler treatment, one of the partial reactions will be called main reaction, denoted by subscript 1, while the other two will be referred as side reactions and marked by subscripts 2 and 3 .

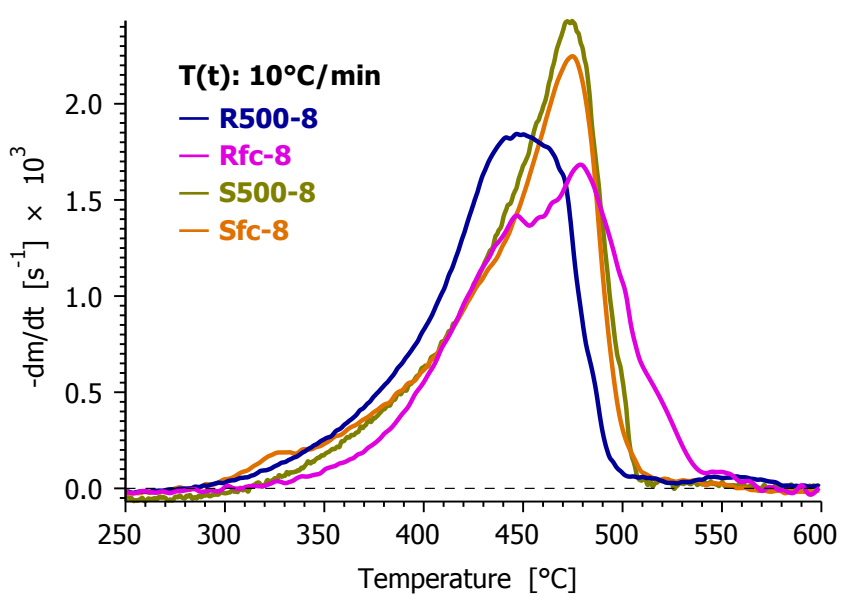

Figure 3. Comparison of the $-d m^{o b s} / d t$ curves of the 8 -bar chars at $10^{\circ} \mathrm{C} / \mathrm{min}$.

The evaluation assuming more than one reaction is facilitated when visible peak tops or at least a shoulder appear on the experimental curves at a linear heating, because they increase the information content of the experimental data. However, most of the experimental - dm/dt curves had a featureless, regular-looking shape. The modelling of the experiments by 3-reaction models revealed strong compensation effects between the variables, hence very different parameter sets could give practically identical fit qualities. In other words, the evaluation proved to be ill-defined without some simplifications. To overcome the problem, the number of unknown parameters were diminished by suitable assumptions. Several ways were tried, as outlined in the Appendix. The assumptions listed below have only slightly affected the fit quality and improved the performance of the model:

(1) The same activation energy was assumed for the three partial reactions at a given sample. This assumption was based on earlier works where similar or identical activation energy values were found to be applicable for the burn-off of rather different chars (chars formed from straw, willow, beech and spruce). ${ }^{22,31}$ 
The $E_{1}=E_{2}=E_{3}$ assumption was applicable for all but one of the chars. The exception was Sample Rfc-8, where an evaluation assuming $E_{1} \neq E_{2}=E_{3}$ gave considerably better fit quality.

(2) Both side reactions were described by $n$-order reactions and $n_{2}=n_{3}$ was assumed. This assumption had only negligible influence on the fit quality. No physical meaning was due to this simplification.

More details are given in the Appendix about the choice of these assumptions, and their effects on the fit quality, mean activation energies, and the shape of the partial curves.

3.4. Model Variant I and Its Results. For the main reaction of the spruce chars the self-accelerating model described in Section 2.4 (eq 6) gave better fit than the simpler $n$-order kinetics. For the forest residue chars the $n$-order model proved to be adequate because it resulted in better fit qualities than eq 6 . The side reactions were approximated by two $n$-order reactions for all chars, as mentioned above. The predicted mass loss rate, $-\mathrm{d} m^{\mathrm{calc}} / \mathrm{d} t$, was calculated as a weighted sum of the three partial reaction rates (eq 8).

This model has 10 unknown parameters for the spruce chars: $E, A_{1}, A_{2}, A_{3}, n_{1}, z_{1}, n_{2}=n_{3}, c_{1}, c_{2}$ and $c_{3}$. The number is 9 for chars R500-1 and R500-8 (because there is no $z_{1}$ in the corresponding model). Sample Rfc-8 has 10 unknown parameters because it has two $E$ values $\left(E_{1}\right.$ and $\left.E_{2}=E_{3}\right)$. Each parameter set is determined from three experiments, hence 3 or 3.33 unknown parameter values fall to an experiment during the evaluation. Altogether 58 parameters were determined from 18 experiments. The resulting parameters are summarized in Table 3 together with a few further characteristics of the results. The assumptions outlined in the previous section are clearly marked / observable in the table. The $E_{1}$ values scattered around a mean of $153 \mathrm{~kJ} / \mathrm{mol}$, while the mean activation energy of the side reactions was a bit lower, $148 \mathrm{~kJ} / \mathrm{mol}$ (due to the lower values at char Rfc-8). The $n$ and $z$ values do not have a direct meaning in char burn-off kinetics; they determine the shape of the $f(\alpha)$ curves, which will be shown in the next section. Notable is the similar kinetics of samples S500-8 and Sfc-8: the kinetics of their main reactions is nearly identical despite the very different production of these chars. The side reactions, however, differ, because Sfc-8 exhibit somewhat more burn-off at low temperatures than S500-8 (See Figure 3.) 
Table 3. Model Variant I: Kinetic Parameters ${ }^{\text {a,b }}$ and Other Characteristics ${ }^{c, d}$

\begin{tabular}{|c|c|c|c|c|c|c|}
\hline Sample & S500-1 & S500-8 & Sfc-8 & R500-1 & R500-8 & Rfc-8 \\
\hline reldev 3 & 3.3 & 3.7 & 2.4 & 4.9 & 5.1 & 3.9 \\
\hline$E_{1}$ & 157.2 & 146.3 & 145.2 & 167.4 & 156.1 & 148.4 \\
\hline$E_{2}, E_{3}$ & 157.2 & 146.3 & 145.2 & 167.4 & 156.1 & 115.5 \\
\hline $\log _{10} A_{1}$ & 8.77 & 7.85 & 7.78 & 9.80 & 8.87 & 8.07 \\
\hline $\log _{10} A_{2}$ & 10.74 & 9.61 & 10.04 & 11.92 & 10.68 & 6.27 \\
\hline $\log _{10} A_{3}$ & 9.63 & 8.47 & 8.53 & 10.44 & 9.27 & 5.45 \\
\hline$n_{1}$ & 1.01 & 0.91 & 0.90 & 0.81 & 0.63 & 0.55 \\
\hline$z_{1}$ & 0.35 & 0.21 & 0.21 & - & - & - \\
\hline$n_{2}, n_{3}$ & 1.43 & 1.31 & 1.90 & 2.01 & 1.25 & 0.62 \\
\hline$c_{1}$ & 0.66 & 0.53 & 0.53 & 0.48 & 0.30 & 0.42 \\
\hline$c_{2}$ & 0.06 & 0.07 & 0.09 & 0.07 & 0.07 & 0.17 \\
\hline$c_{3}$ & 0.28 & 0.41 & 0.39 & 0.42 & 0.57 & 0.34 \\
\hline$T_{0.5,1}$ & 458 & 468 & 467 & 447 & 451 & 464 \\
\hline$T_{0.5,2}$ & 363 & 373 & 351 & 353 & 360 & 416 \\
\hline$T_{0.5,3}$ & 419 & 436 & 433 & 423 & 433 & 480 \\
\hline$\alpha_{1, \max }$ & 0.32 & 0.43 & 0.43 & - & - & - \\
\hline
\end{tabular}

a The dimensions of reldev ${ }_{3}, E$ and $A$ are $\%, \mathrm{~kJ} / \mathrm{mol}$, and $\mathrm{s}^{-1} . n, z$ and $c$ are dimensionless. (See equations $2,6,8$.). $\mathbf{b}$ The main reaction is denoted by index 1 while indices 2 and 3 mark the side reactions. $E_{2}=E_{3}$ and $n_{2}=n_{3}$ for all evaluations, as outlined in the text. ${ }^{\mathbf{c}}$ The reaction temperatures were characterized by the temperatures at which

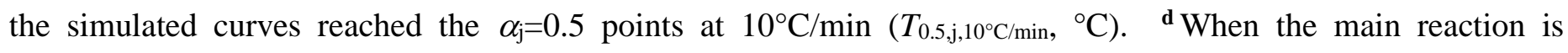
approximated by a self-accelerating kinetics, the $\alpha_{1, \max }$ value belonging to the maximum of $f\left(\alpha_{1}\right)$ is listed.

The partial curves and the fit qualities obtained by the kinetic modelling are shown for two samples in Figure 4. The corresponding figures for the rest of the samples are shown in the Supporting Information. The mass loss rate due to the main reaction is represented by red color, while the blue and green lines belong to the side reactions. The peaks of the main reactions are sharper than those of the side reactions. They are also higher than the peaks of the side reactions except the case of char R500-8. The simulated $-\mathrm{dm} / \mathrm{dt}$ curves 
(black) provided a reasonable approximation to their experimental counterparts (grey). The reldev values indicated in the plots characterize the fit quality of the given plots only; the reldev 3 values, that involve all the three experiments on a char sample, are listed in the first row of Table 3. One can calculate a reldev 18 for all the 18 experiments, as outlined in Section 2.3; it was found to be $4.0 \%$.
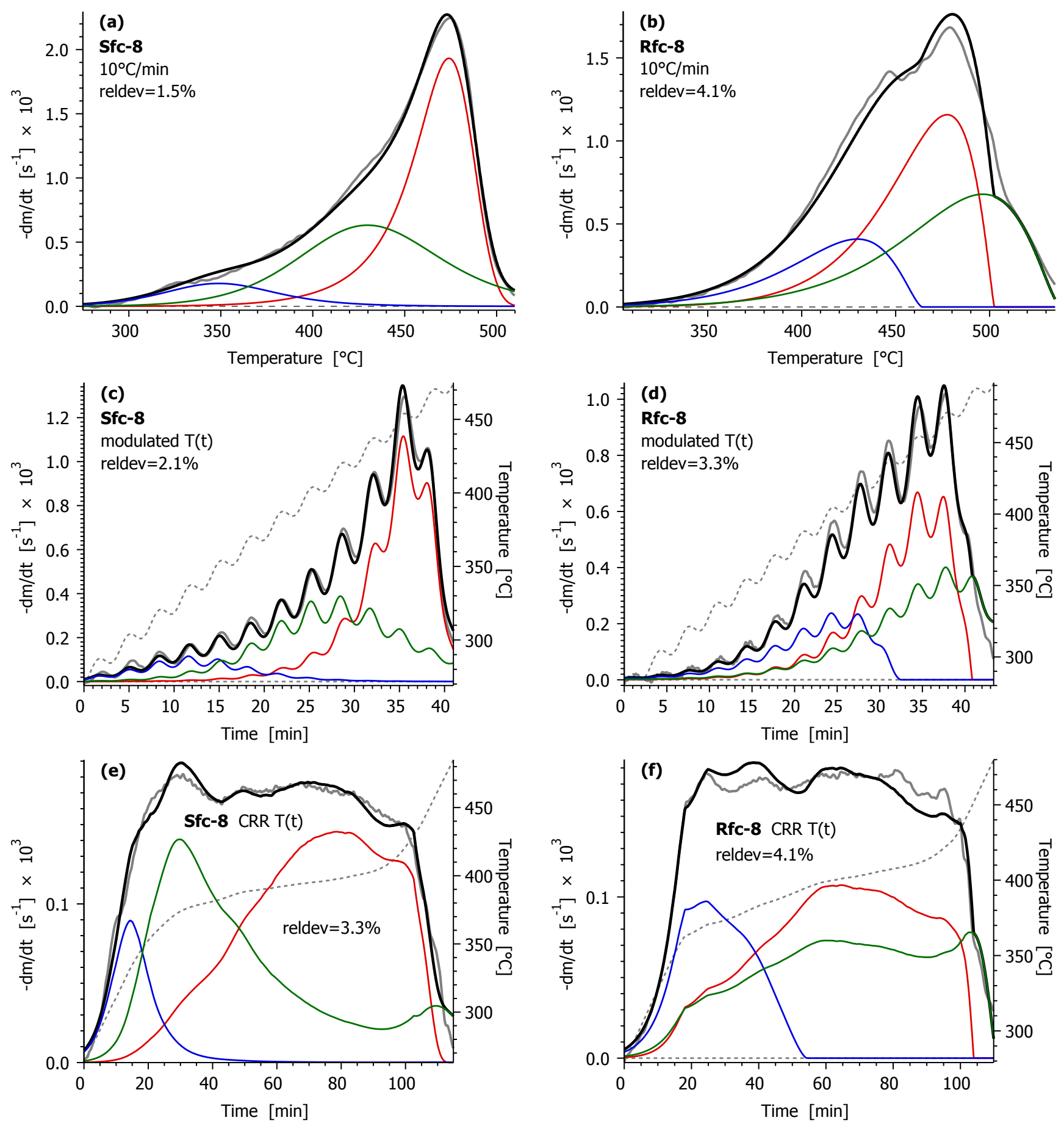

Figure 4. Model Variant I: The partial curves and the fit qualities for samples Sfc-8 and Rfc-8. Notation: temperature (dashed gray line) $-d m^{o b s} / d t$ (solid gray line); $-d m^{\text {calc }} / d t$ (thick black line); main reaction (red solid line), side reactions (blue and green lines). 


\subsection{Model Variant II: Evaluations Assuming Common $\boldsymbol{E}$ for All Reactions. In Model Variant II}

identical activation energy was assumed in all reactions of all chars. This decreased the number of unknown model parameters from 58 to 52 . On the other hand, the 18 experiments had to be evaluated together in a larger least squares minimization because the kinetics of each char depended on the same unknown $E$ value. $E=149.8 \mathrm{~kJ} / \mathrm{mol}$ was obtained in this way. The fit quality worsened somewhat: reldev 18 changed from $4.0 \%$ to $5.1 \%$. Nevertheless, the $f(\alpha)$ functions remained close to the ones obtained in the evaluation of the previous section, as plots (a) and (b) show in Figure 5. The only major difference is at the side reactions of char Rfc-8; the difference between the magenta color curves of Figures $6 \mathrm{a}$ and $6 \mathrm{~b}$ are probably connected to the much lower activation energy of these processes in Model Variant I. The obtained parameters are listed in Table 4. A figure about the obtained fit qualities and partial curves at $10^{\circ} \mathrm{C} / \mathrm{min}$ can be found in the Supporting Information.

As a special check, Model Variant II was also evaluated without the $10^{\circ} \mathrm{C} / \mathrm{min}$ experiments. As described in Section 3.1, the CRR experiments were the most reliable ones in the present series of experiments, while the $10^{\circ} \mathrm{C} / \mathrm{min}$ experiments appeared to be the less reliable. Besides, the information content of the $10^{\circ} \mathrm{C} / \mathrm{min}$ experiments is lower than that of the modulated experiments because the response of the mass loss rate to the modulation waves adds extra information to the modulated experiments. Accordingly, the removal of the $10^{\circ} \mathrm{C} / \mathrm{min}$ experiments from the series of experiments could serve as a test to find out:

(i) Are the remaining 12 experiments still sufficient for the determination of the kinetic parameters?

(ii) Will the parameters from the smaller dataset be similar to the results of the evaluations based on the larger data set?

The determination of the parameters from 12 experiments turned out to be technically more difficult than from 18 experiments because the compensation effects were higher in the smaller dataset. Particularly, the variation of $E$ was counterbalanced by the effect of the other variables. These technical difficulties were overcome so that the evaluation was carried out at constant activation energy values. First the evaluation was carried out at all integer $E$ values between 148 and $157 \mathrm{~kJ} / \mathrm{mol}$. Note that the least squares sums of the individual samples are independent from each other at fixed values of $E$, hence the minimization by the remaining 51 parameters splits into smaller and easier minimizations. After finding the best integer $E$ value, further evaluations were carried out in its vicinity with constant $E$ values with a step size of $0.1 \mathrm{~kJ} / \mathrm{mol}$. This procedure led to $E=152.8 \mathrm{~kJ} / \mathrm{mol}$ with reldev $_{18}=4.55 \%$. A similar procedure was used to refine the results of the 18-experiment evaluation, too, after the direct minimization by all the 52 parameters. The $E=149.8$ $\mathrm{kJ} / \mathrm{mol}$, mentioned above in this section, is the value refined in this way. The difference between the best $E$ from the 12 experiment and 18 experiment datasets is $3 \mathrm{~kJ} / \mathrm{mol}$, which is small compared to the usual 
uncertainties of the non-isothermal reaction kinetics. ${ }^{32}$ The corresponding $f(\alpha)$ functions are shown in Figures $5 c$ and $6 c$. They are similar to the curves in Figures $5 b$ and $6 b$, respectively.
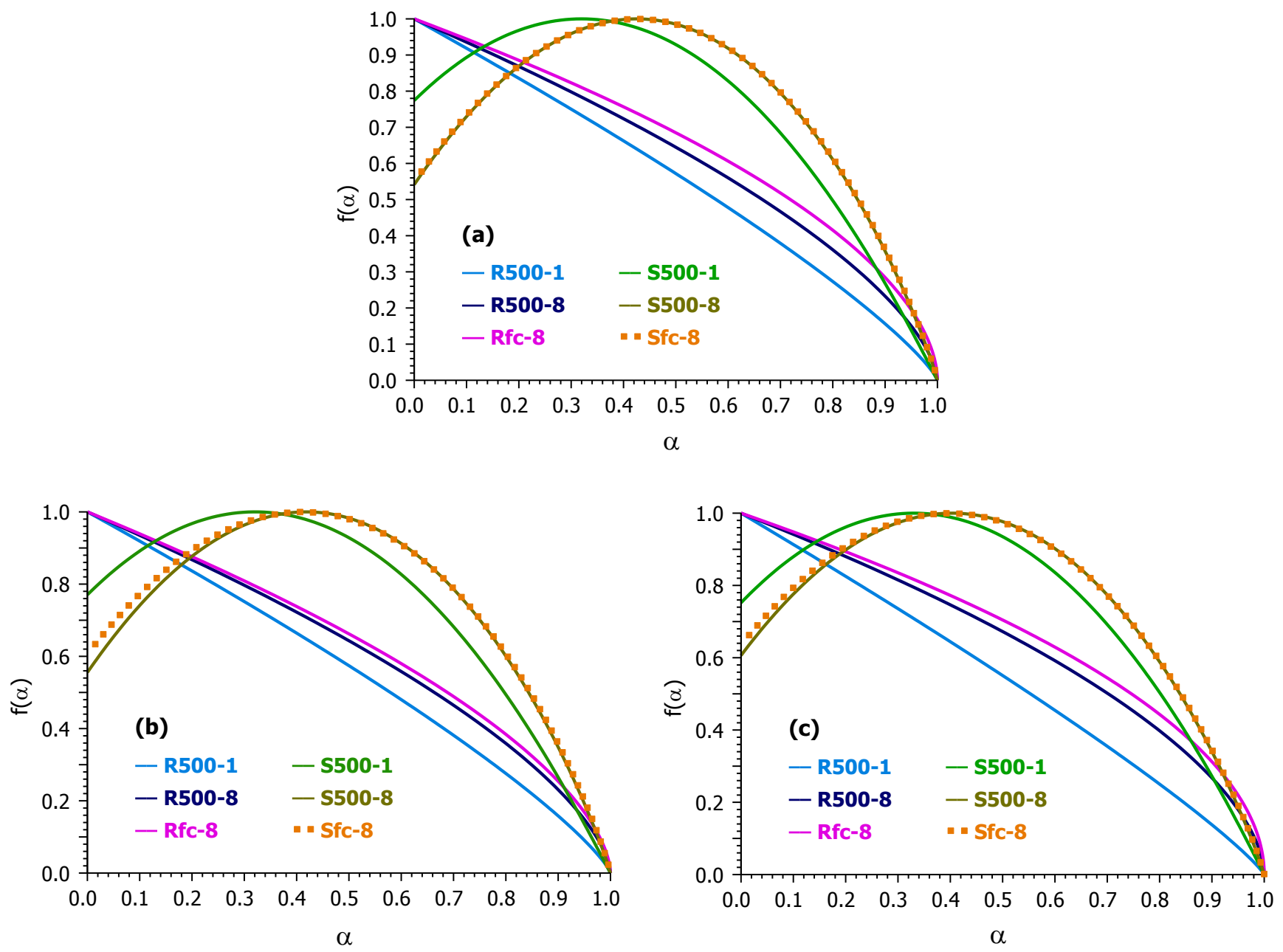

Figure 5. The $\mathrm{f}(\alpha)$ curves of the main reactions obtained by (a) Model Variant I ; (b) Model Variant II; (c) Model Variant II with a reduced dataset of 12 experiments. 

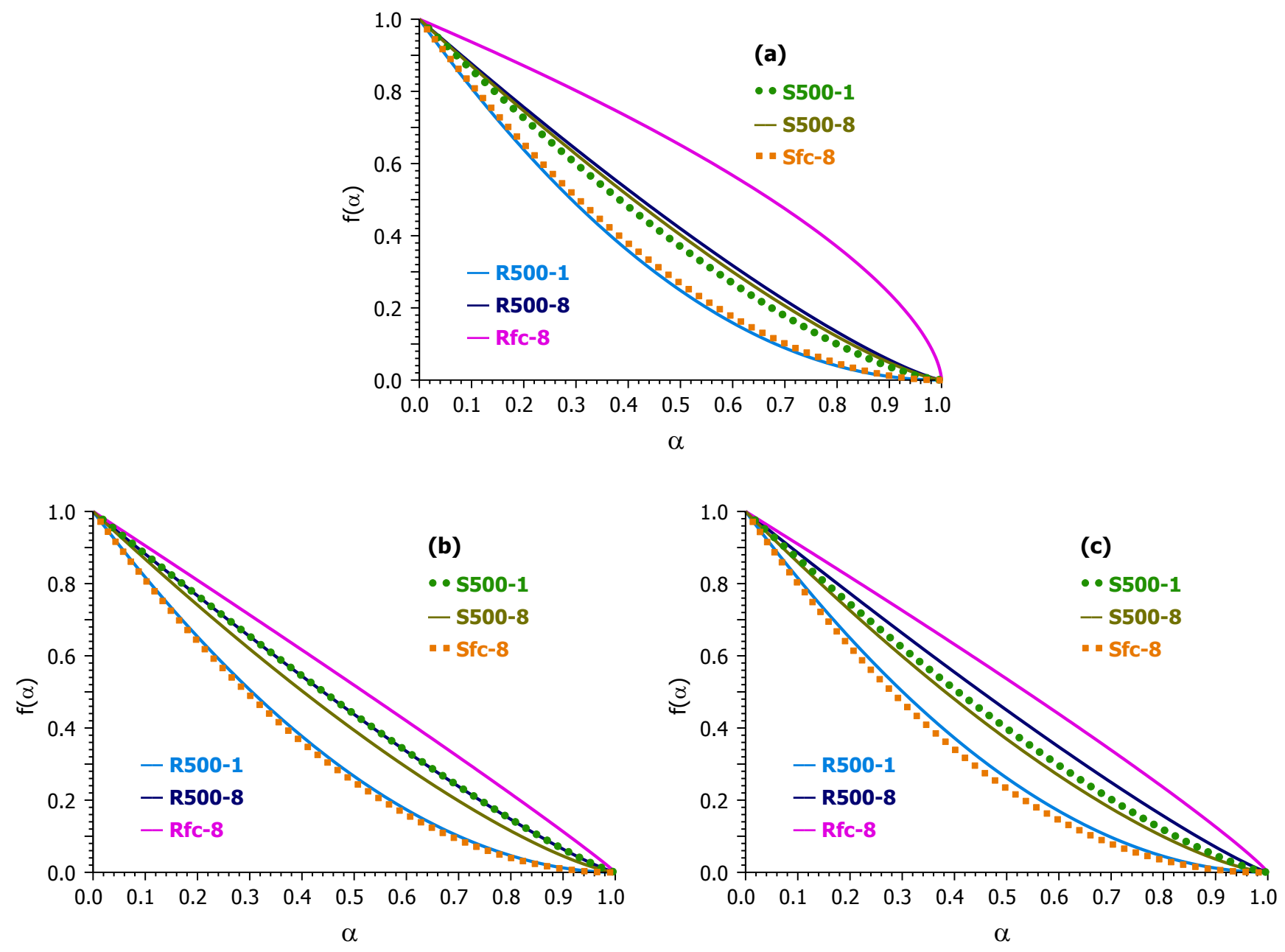

Figure 6. The $f(\alpha)$ curves of the side reactions obtained by (a) Model Variant I ; (b) Model Variant II; (c) Model Variant II with a reduced dataset of 12 experiments.

Table 4. Model Variant II: Kinetic Parameters and Other Characteristics ${ }^{\mathrm{a}, \mathrm{b}}$

\begin{tabular}{lcccccc}
\hline Sample & S500-1 & S500-8 & Sfc-8 & R500-1 & R500-8 & Rfc-8 \\
\hline reldev 3 & 4.2 & 3.9 & 2.9 & 6.4 & 5.4 & 6.8 \\
$\log _{10} A_{1}$ & 8.20 & 8.11 & 8.13 & 8.46 & 8.39 & 8.17 \\
$\log _{10} A_{2}$ & 10.11 & 9.92 & 10.47 & 10.35 & 10.14 & 9.09 \\
$\log _{10} A_{3}$ & 9.10 & 8.77 & 8.92 & 8.98 & 8.75 & 7.72 \\
$n_{1}$ & 1.02 & 0.92 & 0.89 & 0.80 & 0.64 & 0.60 \\
$z_{1}$ & 0.35 & 0.21 & 0.25 & - & - & - \\
$n_{2}, n_{3}$ & 1.19 & 1.35 & 2.00 & 1.91 & 1.19 & 0.95
\end{tabular}




\begin{tabular}{lcccccc}
$c_{1}$ & 0.71 & 0.54 & 0.54 & 0.52 & 0.30 & 0.62 \\
$c_{2}$ & 0.05 & 0.07 & 0.09 & 0.07 & 0.07 & 0.20 \\
$c_{3}$ & 0.24 & 0.40 & 0.38 & 0.38 & 0.57 & 0.13 \\
$T_{0.5,1}$ & 459 & 467 & 466 & 448 & 451 & 464 \\
$T_{0.5,2}$ & 361 & 372 & 351 & 356 & 360 & 413 \\
$T_{0.5,3}$ & 414 & 434 & 431 & 428 & 434 & 499 \\
$\alpha_{1, \max }$ & 0.32 & 0.42 & 0.41 & - & - & - \\
\hline
\end{tabular}

${ }^{\mathbf{a}}$ The results obtained from 18 experiments are presented. $E_{1}=E_{2}=E_{3}=149.8 \mathrm{~kJ} / \mathrm{mol}$. ${ }^{\mathbf{b}}$ See further explanations in the footnotes of Table 3.

3.6. Notes on the Kinetic Results. The self-accelerating kinetics, observed for the spruce chars, is the expected burn-off behavior in the kinetic regime due to the considerations outlined in Section 2.4. At a given activation energy and a constant heating rate the self-accelerating kinetics results in sharper peaks than an $n$ order reaction. This is also true at modulated temperature programs. However, if a char is formed from highly different components, like a forest residue char, the more or less different parts in the char may results in a broader burn-off, and the wider peaks can usually be better described by $n$-order kinetics.

As described in the previous section, an activation energy value of $E \cong 150 \mathrm{~kJ} / \mathrm{mol}$ gave a rougher, but still reasonable kinetic description for all assumed reactions. We shall use this value for a comparison with earlier works. Such a comparison is usually not easy because the kinetics reported in the literature have been based on a wide variation of experimental conditions and evaluation practices. For example, Di Blasi listed $E$ values from 109 to $229 \mathrm{~kJ} / \mathrm{mol}$ in her review. ${ }^{5}$ Accordingly, we restrict the comparison to such works where (i) the experiments were measured in the kinetic regime with checking carefully the possible self-heating problems; (ii) the kinetic evaluation was based on experiments with linear and non-linear temperature programs (to have a broader range of experimental conditions); (iii) a true least squares evaluation was employed (instead of linearizations or other simplifications). Table 5 contains the corresponding comparisons. Despite the different raw materials, different char formation/preparation and different models/assumptions, the $E=150 \mathrm{~kJ} / \mathrm{mol}$ of the present work is near to the middle of the range of Table 5. 
Table 5. Comparison of the Obtained Activation Energy to Earlier Values Obtained by Similar Methods at Similar Experimental Conditions ${ }^{\text {a,b }}$

\begin{tabular}{llll}
\hline E [kJ/mol] & $\begin{array}{l}\text { Raw materials } \\
\text { of the chars }\end{array}$ & $\begin{array}{l}\text { Formation or preparation } \\
\text { of the chars }\end{array}$ & Reference \\
\hline 147 & lignite & $\begin{array}{l}10^{\circ} \mathrm{C} / \mathrm{min} \text { to } 950^{\circ} \mathrm{C}, \\
\text { then } 30 \text { min isothermal } \\
\text { flash carbonization }\end{array}$ & Várhegyi et al. 1996 ${ }^{13}$ \\
$128-152$ & corncob & Várhegyi et al. 2006 ${ }^{14}$ \\
$151-169$ & $\begin{array}{l}\text { wheat straw and } \\
\text { willow wood }\end{array}$ & $\begin{array}{l}\text { the char burn-off section of } \\
\text { biomass combustion in TGA }\end{array}$ & Várhegyi et al. 2012 ${ }^{22}$ \\
& $\begin{array}{l}\text { birch and spruce, } \\
\text { and torrefied woods } \\
\text { prepared from them }\end{array}$ & $\begin{array}{l}\text { the char burn-off section } \\
\text { of the combustion in TGA }\end{array}$ & Tapasvi et al. 2013 \\
& $\begin{array}{l}\text { spruce and } \\
\text { forest residue }\end{array}$ & $\begin{array}{l}\text { atmospheric and pressurized } \\
\text { TGA; flash carbonization }\end{array}$ & present work \\
\hline
\end{tabular}

a See the text for explanations on the terms "similar methods" and "similar experimental conditions". b The models and the employed assumptions were more or less different in the listed works. When the model included devolatilization, too, only the char burn-off reactions were selected for this table.

\section{CONCLUSIONS}

(1) Chars were prepared by three different methods (atmospheric pressure TGA, pressurized TGA and flash carbonization $^{2}$ ) from spruce and forest residue. Their burn-off was studied in the kinetic regime by TGA experiments with linear, modulated and constant reaction rate temperature programs. Due to the huge reaction heat of the char combustion, small sample masses $(0.2-1 \mathrm{mg})$ and slow heating was employed to avoid the self-heating.

(2) The burn-off of the spruce chars was unexpectedly similar despite the substantial differences of their production.

(3) The burn-off of the TGA chars prepared from forest residue at atmospheric pressure and at $0.8 \mathrm{MPa}$ pressure was also quite similar.

(4) More than one reaction was needed for the kinetic modelling of the burn-off because the chars were (obviously) not pure, ideal, homogeneous carbons. For the same reasons, when self-accelerating effects were observed, they were described by a simple empirical model instead of a theoretical model deduced for ideal carbon particles from the literature. Such model variants were constructed which could describe reasonably the chemically and physically inhomogeneous forest residue chars, too.

(5) The selected model variants contained a large number of unknown parameters. The number of parameters were gradually decreased by assumptions that had not worsened the fit quality considerably. 
(6) In a further simplification, a single activation energy value, $E=150 \mathrm{~kJ} / \mathrm{mol}$ proved to be sufficient for a rougher, but still reasonable description of all reactions in all chars, while the rest of the kinetic parameters

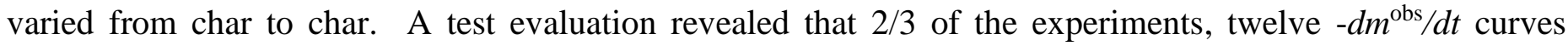
contained sufficient information for the determination of the parameters of this model variant. Accordingly the evaluation was surely on the safe side by employing the 18 experiments of this study.

\section{APPENDIX: THE EFFECTS OF THE ASSUMPTIONS IN MODEL VARIANT I}

As outlined in Sections 3.3 and 3.4, a model of three partial reactions was chosen and the number of unknown parameters were decreased by simplifying assumptions. Herewith more details are given about the effects of the employed assumptions.

The model for the forest residues involved 12 parameters because each partial reaction had an activation energy, a pre-exponential factor, a reaction order, and a weight factor for eq 8 . The number of the parameters was one higher for the wood samples because one of the reactions (Reaction 1) was described by selfaccelerating kinetics (eq 6). The overall fit quality for the 18 experiments was characterized by reldevis. reldev 18 was $3.53 \%$ when the evaluation was carried out without decreasing the number of parameters. This is Evaluation 1 in Table 6. The worse fit quality was observed at sample R500-8 in each evaluations with three partial peaks in Table 6. The corresponding reldev $3,4.99 \%$, is also indicated in Table 6. The number of parameters was gradually decreased by the restrictions indicated in Table 6. Each of these simplification increased slightly reldev $v_{18}$ till the accepted version, Evaluation 6 was reached with reldev $v_{18}=3.98 \%$. The highest reldev 3 was 5.11\%, close to the corresponding value in Evaluation 1. For a comparison, Table 6 also includes Evaluation 7 when the combustion was described by only two partial reactions. In this case reldev 18 was considerably higher, $4.88 \%$, while the highest reldev 3 was 6.57 . Probably this fit quality would still be suitable as a rougher, but simpler approximation. However, the two-reaction model had another problem which will be outlined later in the text.

Unfortunately the significance of the changes in reldev 18 cannot be determined by mathematical statistics because the essential uncertainties of the thermoanalytical experiments are neither random nor independent. ${ }^{21}$ Nevertheless, the fit quality changes accompanying the elimination of a parameter are truly small here as we proceed step by step from Evaluation 1 until Evaluation 6. They are hardly noticeable in the graphical representation of the measured and predicted $-d m / d t$ data. (There are visible differences in the figures belonging to the different evaluations. However, the differences in the overall fit quality for the series of 18 experiments cannot be discerned with the naked eye; for this purpose one has to calculate the corresponding reldev18 values.) 
Table 6: The effects of the reduction of the unknown parameters on the fit quality and on the averages and standard deviations of the activation energies ${ }^{\text {a }}$

\begin{tabular}{|c|c|c|c|c|c|c|c|c|c|}
\hline \multirow{2}{*}{$\begin{array}{l}\text { Evalu- } \\
\text { ation }\end{array}$} & \multirow[t]{2}{*}{$N_{\text {react }} \mathbf{b}$} & \multirow[t]{2}{*}{$N_{\text {up }} \mathbf{c}^{\mathbf{c}}$} & \multicolumn{2}{|c|}{ Assumptions on } & \multirow{2}{*}{$\begin{array}{c}\text { reldev }_{18} \\
\%\end{array}$} & \multirow{2}{*}{$\begin{array}{c}\text { highest } \\
\text { reldev } 3 \\
\%\end{array}$} & \multirow[t]{2}{*}{$E_{1}$} & $E_{2}$ & \multirow[t]{2}{*}{$E_{3}$} \\
\hline & & & $E_{1}, E_{2}, E_{3}$ & $n_{2}, n_{3}$ & & & & $\mathrm{~kJ} / \mathrm{mol}$ & \\
\hline 1 & 3 & 13,12 & none & none & 3.53 & 4.99 & $153(12)$ & $124(14)$ & $152(25)$ \\
\hline 2 & 3 & 12,11 & none & $n_{2}=n_{3}$ & 3.76 & 4.99 & $154(11)$ & $122(19)$ & $151(24)$ \\
\hline 3 & 3 & 12,11 & $E_{2}=E_{3}$ & none & 3.77 & 5.02 & $154(11)$ & $=$ & $150(21)$ \\
\hline 4 & 3 & 11,10 & $E_{2}=E_{3}$ & $n_{2}=n_{3}$ & 3.88 & 5.09 & $154(11)$ & $=$ & $150(22)$ \\
\hline 5 & 3 & 11,10 & $E_{1}=E_{2}=E_{3}{ }^{\mathbf{d}}$ & none & 3.80 & 5.02 & 153 ( 9) & $=$ & $148(18)$ \\
\hline 6 & 3 & 10,9 & $E_{1}=E_{2}=E_{3} \mathbf{d}$ & $n_{2}=n_{3}$ & 3.98 & 5.11 & $153(8)$ & $=$ & $148(18)$ \\
\hline 7 & 2 & 9,8 & none & none & 4.88 & 6.57 & $152(12)$ & $119(17)$ & none \\
\hline
\end{tabular}

a The means and the standard deviations were calculated at each evaluation. (The standard deviations are in parentheses.) Symbol ' $=$ ' means that $E_{2}$ equals to $E_{3} .{ }^{\mathbf{b}} N_{\text {react }}$ is the number of partial reactions. ${ }^{\mathbf{c}} N_{\text {up }}$ is the number of unknown parameters. The first value refers for the wood chars while the second value belongs to the forest residue chars. ${ }^{\mathrm{d}}$ In Evaluations 5 and $6 E_{2}=E_{3}$ was assumed for sample Rfc-8, while $E_{1}=E_{2}=E_{3}$ was supposed for all other samples. (See Section 3.3). Hence $N_{\text {up }}$ for Rfc-8 is one higher here than for R500-1 and R500-8.

The fit quality is obviously an important characteristic of a model. However, other aspects also emerge. We may require that the obtained results would reflect the physical concepts that formed the basis of the modelling. In the present case the main hypothesis was that a real charcoal is not homogeneous, it contains fractions with different reactivity.

When only two partial reactions were assumed (Evaluation 7), the resulting partial curves did not correspond to a more reactive and a less reactive fraction. Here the typical result consisted of a very wide partial curve spreading to the whole temperature domain of the combustion and a sharper partial curve. See the last plot in Figure 7 for an example. Part of the evaluations by three partial reactions also led to a rather wide partial peak at samples S500-8 and Sfc-8. The results obtained for sample Sfc-8 are shown in Figure 7. The wideness of the blue-colored curve was caused by low $E_{2}$ values $(91-100 \mathrm{~kJ} / \mathrm{mol})$ in Evaluations 1,2 and 7. The $E_{2}=E_{3}$ constraint increased the activation energy to 149 and $145 \mathrm{~kJ} / \mathrm{mol}$ in Evaluations 3 and 5 , but the blue curve still remained too wide. In these cases the increase of $E_{2}$ was compensated by an increase of $n_{2}$. 
(See the corresponding $n_{2}$ values in Figure 7.) On the other hand, none of the curves was too wide in Evaluations 4 and 6, because the constraints on $E_{2}$ and $n_{2}$ hindered the convergence to meaningless parameters during the least squares evaluation.
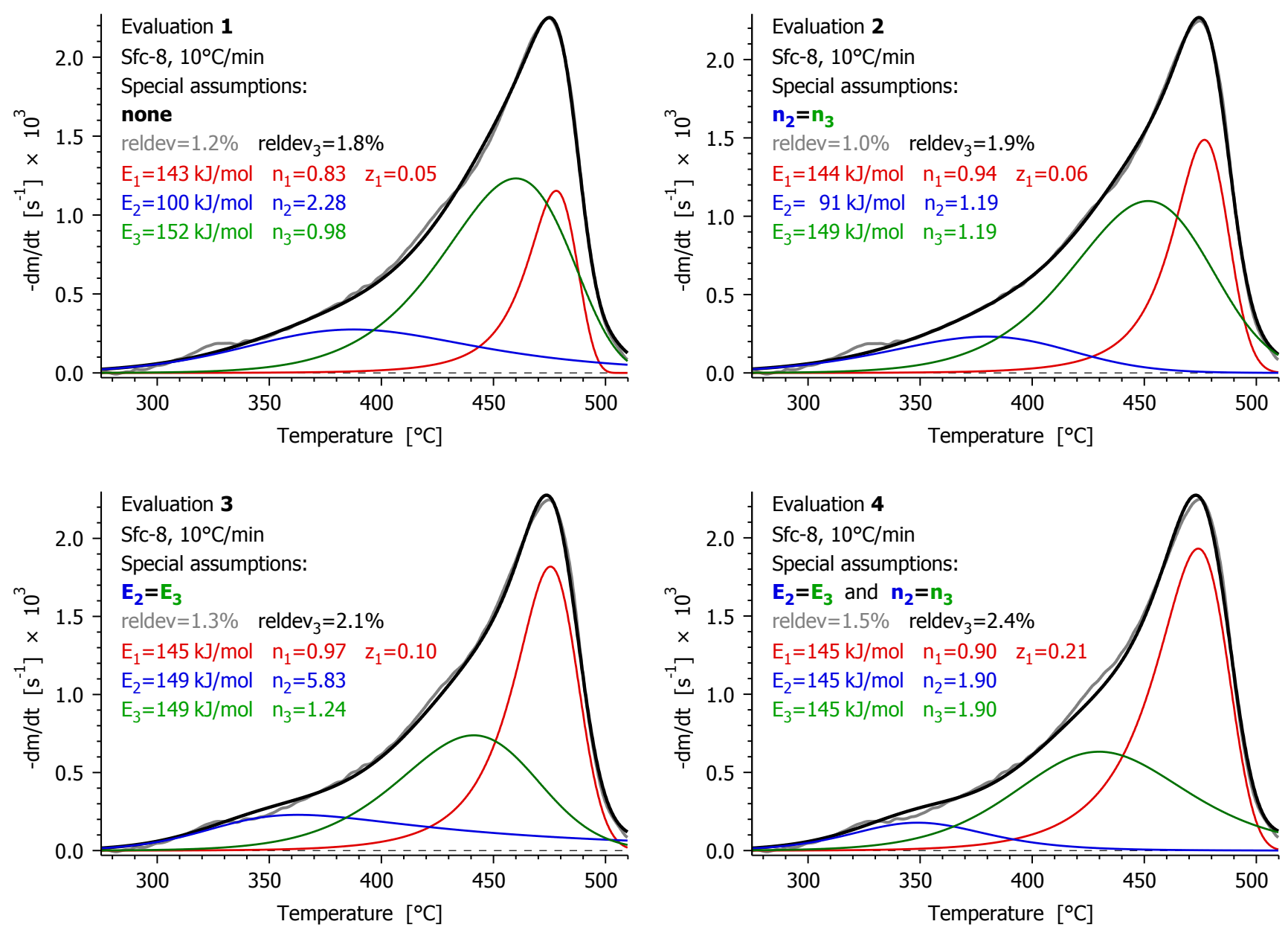

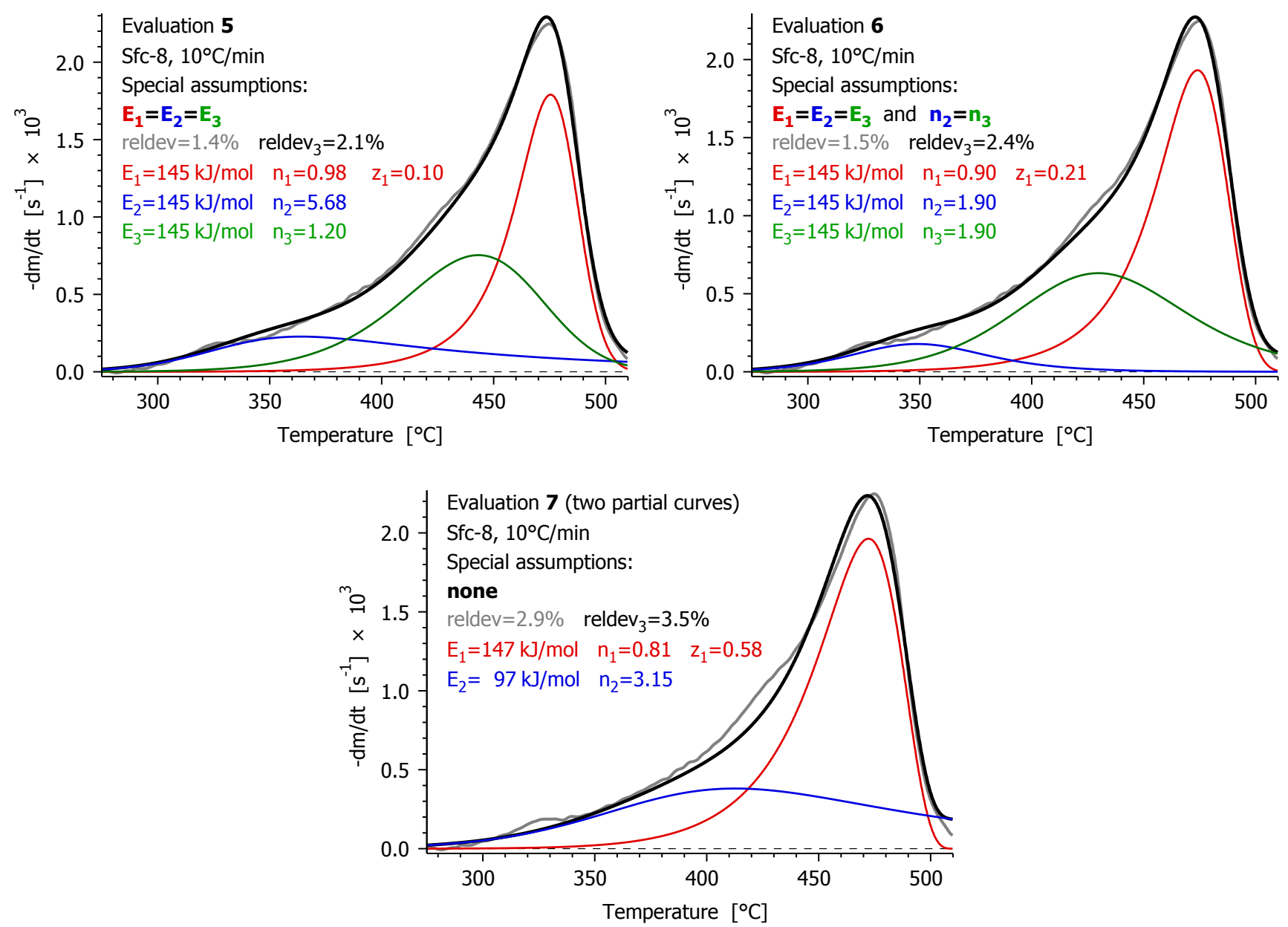

Figure 7. Effects of the employed assumptions in Evaluations 1 - 7. (See Table 6 for the details.) The $10^{\circ} \mathrm{C} / \mathrm{min}$ experiments of Sample Sfc-8 are shown. Notation: $-d m^{o b s} / d t$ (solid gray line); $-d m^{\text {calc }} / d t$ (thick black line); main reaction (red solid line), side reactions (blue and green lines).

Table 6 and Figure 7 illustrate that different model variants can produce practically identical fit qualities. The activation energies $E_{1}$ and $E_{3}$ appeared to be well defined in Table 6: they scattered around nearly the same means in all evaluations. However, the reaction denoted by subscript 2 (the blue curve in the figures) proved to be ill-defined. Its activation energy and reaction order could be altered without a considerable worsening of the fit quality. In this work we preferred such model variants that contained less unknown parameters. Another aspect was that the resulting partial curves would represent each charcoal as a mixture of fractions with different reactivity. 


\section{ASSOCIATED CONTENT}

\section{Supporting Information}

The results are illustrated by further figures representing: (a) The repeatability of the TGA experiments with $0.2 \mathrm{mg}$ initial sample mass; (b) SEM images of the atmospheric pressure chars and the flash carbonization chars; (c) A complete version of Figure 4 (showing all samples and all experiments); (d) The partial curves and fit qualities at the $10^{\circ} \mathrm{C} /$ min experiments when 18 experiments were evaluated by Model Variant II.

\section{AUTHOR INFORMATION}

\section{Corresponding Author}

* To whom correspondence should be addressed.

Email: varhegyi.gabor@t-online.hu or gvarhegyi@gmail.com

\section{ACKNOWLEDGMENT}

The authors acknowledge the financial support by the Research Council of Norway and a number of industrial partners through the project BioCarb+ ("Enabling the biocarbon value chain for energy").

\section{NOMENCLATURE}

$\alpha=$ reacted fraction (dimensionless)

$A=$ pre-exponential factor $\left(\mathrm{s}^{-1}\right)$

$c=$ weight factor of a partial curve in eq 8

$E=$ activation energy $(\mathrm{kJ} / \mathrm{mol})$

$f=$ an empirical function in eq 1 expressing the change of the reactivity as the reactions proceed (dimensionless)

$h=$ the height of an experimental $-\mathrm{dm} / \mathrm{dt}$ curve in equations $3-5\left(\mathrm{~s}^{-1}\right)$

$m=$ the sample mass normalized by the sample mass at $120^{\circ} \mathrm{C}$ (dimensionless)

$n=$ reaction order with respect of $1-\alpha$ (dimensionless)

of $=$ the objective function (eq 3 ) which is minimized in the least squares evaluation (dimensionless)

$N=$ number of experiments evaluated together by the method of least squares

$N_{\text {points }}=$ number of evaluated data on a given experimental curve in eq 3

$N_{\text {react }}=$ number partial reactions

$N_{\text {up }}=$ number of unknown parameters

$R=$ gas constant $\left(8.3143 \times 10^{-3} \mathrm{~kJ} \mathrm{~mol}^{-1} \mathrm{~K}^{-1}\right)$

reldev $=$ the root mean square difference between the predicted and observed data expressed as per cent of the corresponding peak height by eq $5(\%)$ 
reldev $v_{3}$, reldev $v_{8}=$ the root mean square of the reldev values of 3 and 18 experiments, respectively $(\%)$

$t=$ time $(\mathrm{s})$

$T=$ temperature $\left({ }^{\circ} \mathrm{C}, \mathrm{K}\right)$

$z=$ formal parameter in eq 6 (dimensionless)

\section{REFERENCES}

1. Antal, M. J.; Grønli, M. The art, science, and technology of charcoal production. Ind. Eng. Chem. Res. 2003, 42, 1619-1640.

2. Antal, M. J.; Mochidzuki, K.; Paredes, L. S. Flash carbonization of biomass. Ind. Eng. Chem. Res. 2003, 42, 3690-3699.

3. Bergseng, E.; Eid, T.; Løken, Ø.; Astrup, R. Harvest residue potential in Norway - A bio-economic model appraisal. Scand. J. Forest Res. 2013, 28, 470-480.

4. Bioenergi i Norge (Bioenergy in Norway). Norwegian Water Resources and Energy Directorate, NVE report 41, 2014, Oslo, Norway, pp 98 (in Norwegian), http://webby.nve.no/publikasjoner/rapport/2014/rapport2014_41.pdf

5. Di Blasi, C. Combustion and gasification rates of lignocellulosic chars. Prog. Energy Combust. Sci. 2009, $35,121-140$.

6. Daood, S. S.; Munir, S.; Nimmo, W.; M. Gibbs, B. M. Char oxidation study of sugar cane bagasse, cotton stalk and Pakistani coal under 1\% and 3\% oxygen concentrations. Biomass Bioenergy 2010, 34, 263-271.

7. Sahu, S. G.; Sarkar, P.; Chakraborty, N.; Adak, A. K. Thermogravimetric assessment of combustion characteristics of blends of a coal with different biomass chars. Fuel Proc. Technol. 2010, 91, 369-378.

8. Tushar, M. S. H. K.; Mahinpey, N.; Khan, A.; Ibrahim, H.; Kumar, P.; Idem, R. Production, characterization and reactivity studies of chars produced by the isothermal pyrolysis of flax straw. Biomass Bioenergy 2012, 37, 97-105.

9. Pottmaier, D.; Costa, M.; Farrow, T.; Oliveira, A. A. M.; Alarcon, O.; Snape, C. Comparison of rice husk and wheat straw: from slow and fast pyrolysis to char combustion. Energy Fuels 2013, 27, 7115-7125.

10. Trubetskaya, A; Jensen, P. A.; Jensen, A. D.; Steibel, M.; Spliethoff, H.; Glarborg, P.; Larsen, F. H. Comparison of high temperature chars of wheat straw and rice husk with respect to chemistry, morphology and reactivity. Biomass Bioenergy 2016, 86, 76-87.

11. Kissinger, H. E. Reaction kinetics in differential thermal analysis. Anal. Chem. 1957, 29, 1702-1706.

12. Tilghman, M. B.; Mitchell, R. E. Coal and biomass char reactivities in gasification and combustion environments. Combust. Flame 2015, 162, 3220-3235.

13. Várhegyi, G.; Szabó, P.; Jakab, E.; Till, F.; Richard J-R. Mathematical modeling of char reactivity in Ar$\mathrm{O}_{2}$ and $\mathrm{CO}_{2}-\mathrm{O}_{2}$ mixtures. Energy Fuels 1996, 10, 1208-1214.

14. Várhegyi, G.; Mészáros, E.; Antal, M. J., Jr.; Bourke, J.; Jakab, E. Combustion kinetics of corncob charcoal and partially demineralized corncob charcoal in the kinetic regime. Ind. Eng. Chem. Res. 2006, 45, 49624970. 
15. Li, J.; Bonvicini, G.; Biagini, E.; Yang, W.; Tognotti, L. Characterization of high-temperature rapid char oxidation of raw and torrefied biomass fuels. Fuel 2015, 143, 492-498.

16. Naredi, P.; Yeboah, Y. D.; Pisupati, S. V. Effect of furnace purging on kinetic rate parameter determination using isothermal thermogravimetric analysis. Energy Fuels 2011, 25, 4937-4943.

17. Wang, L.; Skreiberg, Ø.; Grønli, M.; Specht, G. P.; Antal, M. J. Is elevated pressure required to achieve a high fixed-carbon yield of charcoal from biomass? Part 2: The importance of particle size. Energy Fuels 2013, 27 , 2146-56.

18. Wang, L.; Sandquist, J.; Várhegyi, G.; Matas Güell, B. $\mathrm{CO}_{2}$ Gasification of Chars Prepared from Wood and Forest Residue. A Kinetic Study. Energy Fuels, 2013, 27, 6098-6107.

19. High resolution thermogravimetric analysis - A new technique for obtaining superior analytical results. TA Instruments report TA-023. Available at: http://www.tainstruments.co.jp/application/pdf/Thermal_Library/Applications_Briefs/TA023.PDF

20. Lever, T.; Haines, P.; Rouquerol, J.; Charsley, E. L.; Van Eckeren, P.; Burlett, D. J. ICTAC nomenclature of thermal analysis (IUPAC Recommendations 2014). Pure Appl. Chem. 2014, 86, 545-553.

21. Várhegyi, G. Aims and methods in non-isothermal reaction kinetics. J. Anal. Appl. Pyrolysis 2007, 79, 278-288.

22. Várhegyi, G.; Sebestyén, Z.; Czégény, Z.; Lezsovits, F.; Könczöl, S. Combustion kinetics of biomass materials in the kinetic regime. Energy Fuels 2012, 26, 1323-1335.

23. Várhegyi, G.; Chen, H.; Godoy, S. Thermal decomposition of wheat, oat, barley and Brassica carinata straws. A kinetic study. Energy Fuels 2009, 23, 646-652.

24. Kolda, T. G.; Lewis, R. M.; Torczon, V. Optimization by direct search: New perspectives on some classical and modern methods. SIAM Rev. 2003, 45, 385-482.

25. Várhegyi, G.; Szabó, P.; Mok W. S. L., Antal, M. J., Jr. Kinetics of the thermal decomposition of cellulose in sealed vessels at elevated pressures. Effects of the presence of water on the reaction mechanism. J. Anal. Appl. Pyrolysis 1993, 26, 159-174.

26. Bhatia; S. K; Perlmutter, D. D. A random pore model for fluid-solid reactions: I. Isothermal kinetic control. AIChE J. 1980, 26, 379-386.

27. Gavalas, G. R. A random capillary model with application to char gasification at chemically controlled rates. AIChE J. 1980, 26, 577-585.

28. Baltic Bioenergy and Industrial Charcoal project (BalBiC), http://www.balbic.eu/en/en_GB/what_is_biocoal/

29. Mu, J.; Perlmutter, D. D. Thermal decomposition of carbonates, carboxylates, oxalates, acetates, formates, and hydroxides. Thermochim. Acta 1981, 47, 207-218.

30. Khan, N.; Dollimore, D.; Alexander, K; Wilburn F. W, The origin of the exothermic peak in the thermal decomposition of basic magnesium carbonate. Thermochim. Acta 2001, 367-368, 321-333.

31. Tapasvi, D.; Khalil, R.; Várhegyi, G.; Skreiberg, Ø.; Tran, K.-Q.; Grønli, M. Kinetic behavior of torrefied biomass in an oxidative environment. Energy Fuels, 2013, 27, 1050-1060.

32. Grønli, M.; Antal, M. J., Jr.; Várhegyi, G., A round-robin study of cellulose pyrolysis kinetics by thermogravimetry. Ind. Eng. Chem. Res. 1999, 38, 2238-2244. 